\title{
TEKNOLOGI EKONOMI KREATIF, UPAYA MEMANFAATKAN LIMBAH KULIT KERANG MEMILIKI NILAI EKONOMI TINGGI DI DESA KARANG SURAGA KECAMATAN CINANGKA
}

\author{
Euis Amilia \\ Universitas Banten Jaya, Jl Syech Nawawi Albantani Serang, Banten, Indonesia \\ E-mail: euisamilia@unbaja.ac.id
}

\begin{abstract}
The aim of the Student Work Lecture (KKM) in 2019, about Creative Economy Technology is to improve the skills of the village community in Karang Suraga Village, especially housewives, village youths and students of SMK 1 Cinangka. The partners of this activity are non-productive communities in Karang Suraga village, Kec. Cinangka. The problem faced is not yet knowing the use of conch shells to produce useful products and have a sale value. The method of implementing this service is through (1) Surveying through observations, interviews, and analysis of village problems and potentials, (2) Training on shellfish creativity. The result of this program is the increase in community knowledge and skills regarding shellfish waste treatment. This program is expected to facilitate the community in increasing their knowledge and skills in processing used materials into useful products and selling values, so that Karang Suraga a villager become productive communities.
\end{abstract}

Keywords: Community Utilization, Waste Management, Seashells.

\begin{abstract}
ABSTRAK
Tujuan Kuliah Kerja Mahasiswa (KKM) Tahun 2019, tentang Teknologi Ekonomi Kreatif adalah untuk meningkatkan keterampilan masyarakat Desa di Desa Karang Suraga, khususnya Ibu rumah tangga, pemuda-pemudi desa beserta siswa-siswi SMK 1 Cinangka. Mitra dari kegiatan ini adalah masyarakat non produktif di desa Karang Suraga, Kec. Cinangka. Permasalahan yang dihadapi yaitu belum mengetahui pemanfaatan kulit kerang untuk menghasilkan produk yang berguna dan memiliki nilai jual. Metode pelaksanaan pengabdian ini yaitu melalui (1) Survey melalui pengamatan, wawancara, dan analisis permasalahan dan potensi desa, (2) Pelatihan kreativitas kulit kerang. Hasil dari program ini adalah bertambahnya pengetahuan dan keterampilan masyarakat mengenai pengolahan limbah kulit kerang, Program ini diharapkan dapat memfasilitasi masyarakat dalam meningkatkan pengetahuan dan keterampilan dalam mengolah bahan bekas menjadi produk yang berguna dan memiliki nilai jual, sehingga masyarakat desa karang suraga menjadi masyarakat yang produktif.
\end{abstract}

Kata Kunci: Memanfaatkan Masyarakat, Pengolahan Limbah, Kulit Kerang.

\section{PENDAHULUAN}

Sebelum tahun1820 Desa Karang Suraga Kecamatan Cinangka Kabupaten Serang namanya adalah Desa Tawing yang dikepalai oleh seorang kuwu atau istilah kepala desa yang dikenal pada zaman tersebut yang bernama Ki Tawing yang lokasi desanya di Kp. Tawing, Ki Tawing Menjabat sebagai kepala desa sampai tahun 1850. Setelah itu terjadi pergantian kepemimpinan kepala desa ke-2 menggantikan Ki Tawing yaitu bernama Suryadilaga dan 
kedudukan kantor kepala desanya pun pindah ke bukit Karang Bolong yang sangat unik dan sakral pada kepemimpinan Suryadilaga adalah terjadi perubahan nama desa yang tadinya bernama desa Tawing diubah menjadi Desa Karang Suraga. Asal usul nama Desa Karang Suraga diambil dari kata "Karang" pada sebuah nama tempat yaitu Karang Bolong sedangkan kata "Suraga" diambil dari singkatan nama kepala desanya yaitu Suryadilaga.

Secara geografis, letak Indonesia berada di tengah-tengah belahan dunia. Indonesia adalah Negara kepulauan yang dikelilingi oleh laut-laut yang luas, sehingga biota-biota laut banyak yang hidup di perairan tersebut, seperti ikan, terumbu karang, siput dan kerangkerangan, itulah kenapa disebut dengan desa karang suraga. Negara Indonesia yang merupakan Negara tropis, sehingga potensial untuk berkembang, bahkan kerang-kerangan serta di dukunng dengan temperatur yang tinggi selama dan sepanjang tahun dan waktu. Siang dan malam relatif sama panjangnya serta didukung dengan tekanan udara yang relative rendah. Tiupan angina yang sejuk dengan kelembaban dan curah hujan yang cukup dengan kedalaman laut yang bervariasi, maka akan banyak ditemukan berbagai siput dan kerang-kerangan yang beraneka macam bentuk kulit dan cangkangnya.

Potensi utama desa Karang Suraga yaitu pada bidang Pariwisata, pada bidang tersebut mayoritas masyarakat adalah pedagang. sedangkan potensi dibidang lainnya adalah persawahan, perkebunan, dan perikanan.Pada bidang perkebunan komoditi utamanya yaitu pisang, tangkil, kelapa dll.Tanaman ini banyak dibudidayakan oleh masyarakat. Hasil dari perkebunan tersebut hanya di ambil buah dan daunnya saja untuk di jual kepasar - pasar.selain itu desa Karang suraga pun memiliki potensi lain di bidang industri skala rumah tangga seperti industry kerajinan kerang, dan pembuatan furnitur. Pada dasarnya yang dimaksud dengan nama kerangkerangan, bahasa latinnya Moluska adalah biota laut yang sebagian besar hidup di pasir yang berair dekat pantai dan juga ada yang habitatnya di karang-karang, yang masuk golongan ini dinamakan keong-keongan atau siput, tetapi orang awam selalu menamakannya kerangkerangan yang masuk kedalam golongan keong-keongan atau siput pada umumnya memiliki cangkang satu, seperti Keong Patam, Keong Jagung, Keong Nanas, Mata Lembu, Keong Bor dan yang lebih besar lagi namanya Kepala Kambing. (Lampiran).

Dan yang termasuk ke dalam golongan kerang-kerangan seperti Kerang Bulu, Kerang Dara, Kerang Melati, Kerang Kepah dan Kerang yang lebih besar, yaitu Winga (Lampiran). Jenis-jenis kerang yang biasa di konsumsi di Indonesia adalah kerang hijau, kerang batik, kerang tahu, kerang dara, kerang bambu, kerang bulu, kerang simping, kupang dan tiram. Desain suatu produk kerajinan memegang peran sangat penting dalam meraih peluang pasar, di samping kualitas dan kuantitas suatu produksi, untuk membuat suatu produksi suatu apapun, diperlukan sebuah desain. Desain bisa dibaca dan diliat melalui indera mata serta prasa melalui 
pengalaman estetika, hal ini berarti setelah produk yang paling sederhana sampai dengan produk dengan menggunakan teknologi. Semuanya dibuat berdasarkan pola rencana tertentu atau disebut desain pada pembuatan produk yang sederhana.

\section{METODE}

Metode yang digunakan selama proses pelatihan adalah (1). Pembekalan kepada mahasiswa pendamping lapangan yang dilaksanakan di desa karang suraga dengan pemateri Bp.Nono dari Pusat Pelatihan Mandiri kelautan dan Perikanan (P2MKP) karya Virgo di bidang kerajinan kerang. (2). Pelaksanaan pelatihan pada masyarakat di desa karang suraga yang diawali dengan pemberian materi mengenai berbagai macam kerang dan ciri-cirinya serta mengetahui cara penggunannya. (3). Demonstrasi pembuatan bingkai foto.yang diperagakan oleh bp. Nono dan mahasiswa pendamping KKM. (4). Praktek pembuatan bingkai foto dengan Tim mahasiswa KKM.

a) Proses pengolahan bahan kerang menjadi bersih

Kerang-kerangan yang kita peroleh dari laut tentunya tidak langsung bersih. Kondisinya masih dalam keadaan kotor, penuh tanah dan lumut, terlebih dahulu kita harus mencucinya atau membersihkannya dengan cara kimiawi. Bahan-bahan dan alat-alat yang perlu disiapkan untuk proses pencucian secara kimiawi sebagai berikut :
1. Bahan kerang atau siput
7. Air.
2. Kaporit
8. Sarung tangan dari karet
3. $\mathrm{HCl}$
9. Masker
4. Bak (ukuran 30 liter air)
10. Kaca mata
5. Ember (ukuran 10 liter air)
11. Bambu/kayu Diameter $5 \mathrm{~cm}$, panjang 1 meter
6. Gayung

Bahan kerang atau siput yang masih kotor, kita cuci terlebih dahulu dengan air bersih, lalu masukkan ke dalam air bak (yang berukuran 30 liter air). Setelah bak sudah terisi dengan bahan kerang, lalu tuangkan air bersih dengan menggunakan ember hingga penuh, sehingga bagian atas kerang tidak terlihat oleh air (liput). Sebelum melanjutkan ke tahap berikutnya gunakan masker dan kacamata polos sebagai pengaman. Kemudian taburi kaporit sebanyak 4 ons, lalu aduk perlahan-lahan dengan menggunakan kayu atau bambu berdiameter $5 \mathrm{~cm}$ panjang 1 meter. Proses perendaman memerlukan waktu selama 5 jam agar kaporit bisa larut.dan bereaksi pada bahan kerang. Ketika proses kimia $\mathrm{HCl}$ (Asam Klorida), kerang yang sudah di bilas air bersih masukkan kedalam ember ukuran 10 liter air sampai penuh bak, isi dengan air sebanyak 3 liter, air aduk sampai rata. 
Sesudah bak berisi campuran air $+\mathrm{HCl}$, masukkan bahan satu ember kedalamnya aduk secara cepat dengan menggunakan bambi//kayu dan jangan lupa sebelum mengaduk gunasarung tangan yang terbuat dari bahan karet, masker untuk penutup hidung dan kacamata pelindung mata. Ketika proses pengadukan sedang berlangsung, reaksi kimia akan menimbulkan busa sangat significant dan kemudian hilang secara perlahan-lahan. Itu bertanda kadar $\mathrm{HCl}$ sudah larut semuanya. Bahan karang bisa langsung di bilas air bersih dan kerangpun hasilnya bersih sempurna.

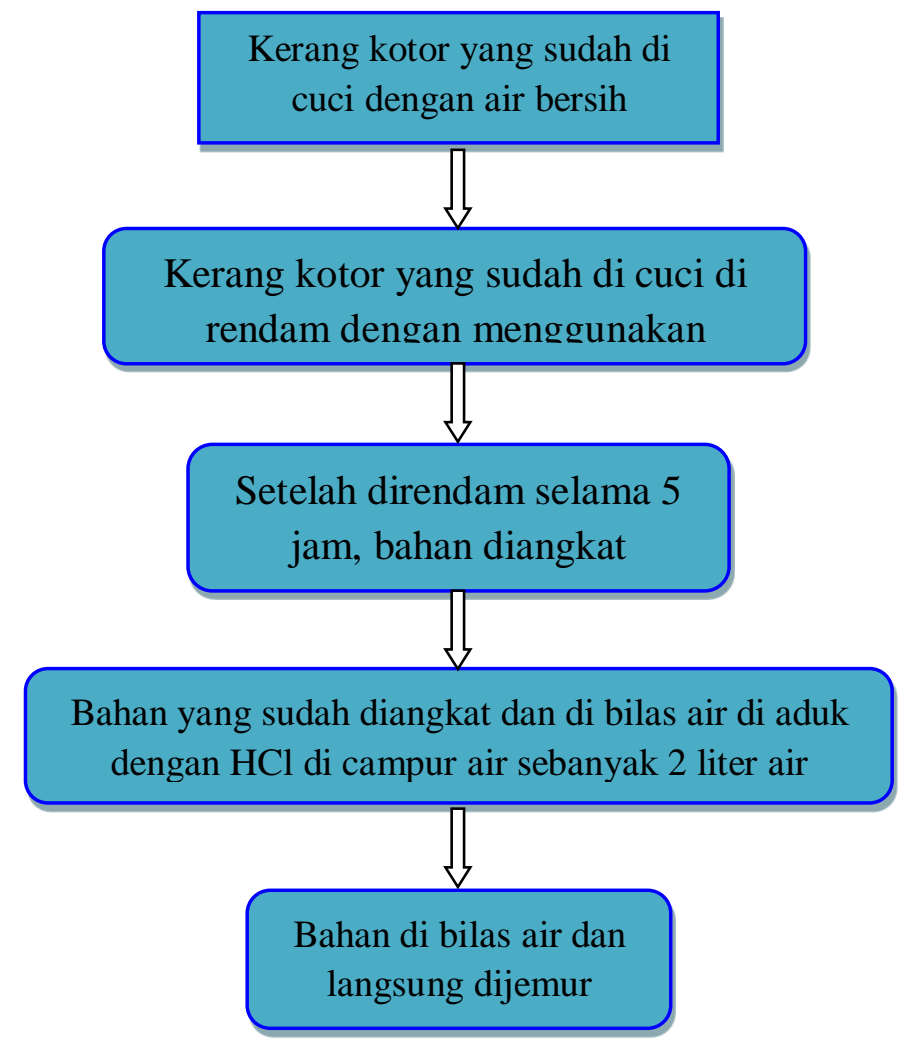

\section{Diagram 1. Alur Proses pengolahan bahan kerang menjadi bersih}

b) Proses Pembuatan Bingkai Foto

Bingkai foto yang produksi Karya Virgo, mempunyai berbagai macam ukuran, mulai dari 2 R, 3R, 5R, 10R dan 20R serta bermacam-macam desainnya, seperti contoh di bawah ini :

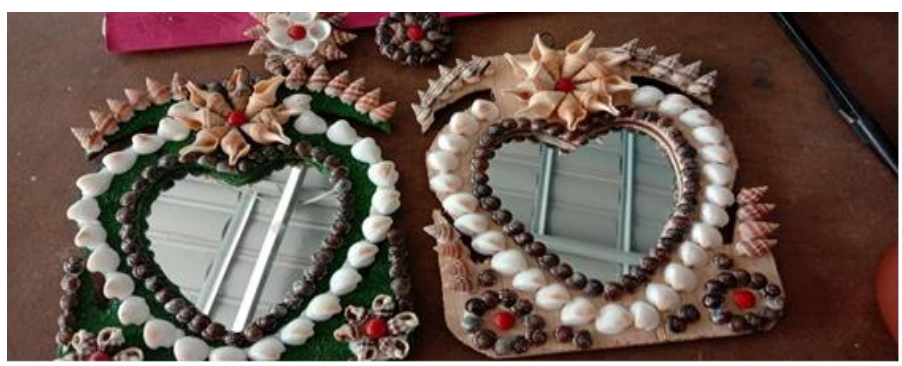

Gambar 1. Contoh Bingkai Foto Ukuran 2R 
Langkah awal cara pengerjaannya, dan yang perlu dipersiapkan adalah:

1. Bahan Kerang atau Keong:
a. Keong Patang
e. Kerang putih bulat
b. Keong Tali
f. Kerang Lamis atau Kepah
c. Keong Nanas
g. Pasir halus berwarna
d. Keong Lancip Kuning

2. Bahan-bahan pembantu:
a. Lem putih atau sintetis
e. Kaca
b. Aci
f. Karton
c. Triplek
g. Timer
d. Pernis

3. Alat-alat seperti:
a. Kuas
b. Gergaji atau triplek
c. Glue Gun (Lem Tembak)
d. Penusuk Lubang
e. Tang potong
f. Pisau Cutter

Setelah bahan dan alat disiapkan, ambil triplek terlebih dahulu untuk dipola dengan menggunakan cetakan sesuai dengan pola yang diinginkan dengan menggunakan pensil, lalu potong dengan gergaji triplek. Setelah itu pola yang sudah terpotong di amplas sampai bersih untuk diberi pasir warna, media triplekterlebih dahulu diolesi lem, kemudian ditaburi pasir yang sudah diberi warna sampai merata, lalu dijemur hingga kering.

Pola bingkai foto yang akan di buat adalah bentuk hati (Bingkai Love), setelah bagian pasirnya kering, permukaan pasir langsung bisa ditempeli kerang (dekorasi) gunakan lem untuk media penempelan kerang, mula-mula kita menempeli pinggir bingkai foto dengan Keong Patam atau Keong Saar, kemudian bagian atasnya tempeli dengan Keong Lancip atau Kerang Kepah membentuk bunga lalu samping kanan, kiri atas sayap bunga dengan Keong Nanas, maka selesailah pembuatan bingkai foto tersebut, agar lem lebih cepat kering, maka bingkai foto kembali di jemur. Setelah bingkai foto kering, pengerjaan terakhir adalah finishing dengan memberi pernis yang dicampuri Thinner, agar hasilnya lebih indah. 


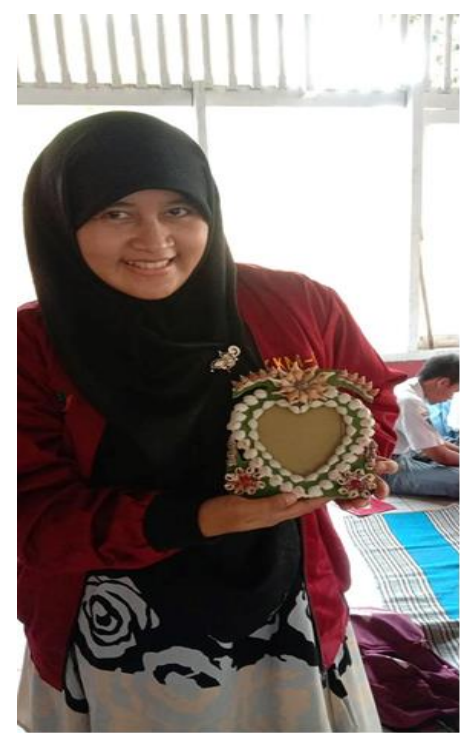

\section{Gambar 2. Ukuran Foto 2R Tunggal}

c) Pembuatan Kerajinan Binatang Landak atau Trenggiling

Bahan dan alat yang perlu dilengkapi diantaranya adalah :

1. Keong Saar

2. Keong Krucut

3. Keong Kuning Lancip

4. Keong Tali

5. Kerang Putih Bulat

Bahan pembantu diantaranya:
1. Lem
4. Pernis
2. Aci
5. Timer
3. Sterefoam
6. Kuas

Alat-alat diantaranya:

1. Glue Gun (Lem Tembak)

2. Pisau Cutter

3. Mangkuk

Cara pembuatannya:

1. Irislah Steroform untuk membuat pola badan landak dan Trenggiling, Steroform yang digunakannya adalah yang tebalnya $5 \mathrm{~cm}$. Untuk membuat badan landak dan Tringgiling ukurannya adalah panjang 9,5 $\mathrm{cm}$ dan lebar 5,5 $\mathrm{cm}$. Mengiris steroform dari bagian atas mengarah ke bawah dan seterusnya.

2. Setelah pola badan Landak atau Tringgiling terbentuk, gunakan Keong Kuning Lancip untuk membentuk kaki, lubangi sedikit saja untuk memasang Keong Kuning Lancip 
untuk kaki, gunakan lem tembak untuk memasang kaki, begitu pula untuk memasang kepala dan ekornya.

3. Pola badan yang sudah diberi kaki, ekor dengan Keong Kuining Lancip langsung bias di hias (temple dengan Keong Saar) mulai bagian belakang pas bagian ekor. Setelah semuanya selesai dan sudah kering untuk finishingnya, polesi kerang dengan pernis dengan menggunakan kuas, maka selesailah pembuatan kerajinan landak dari kerang.

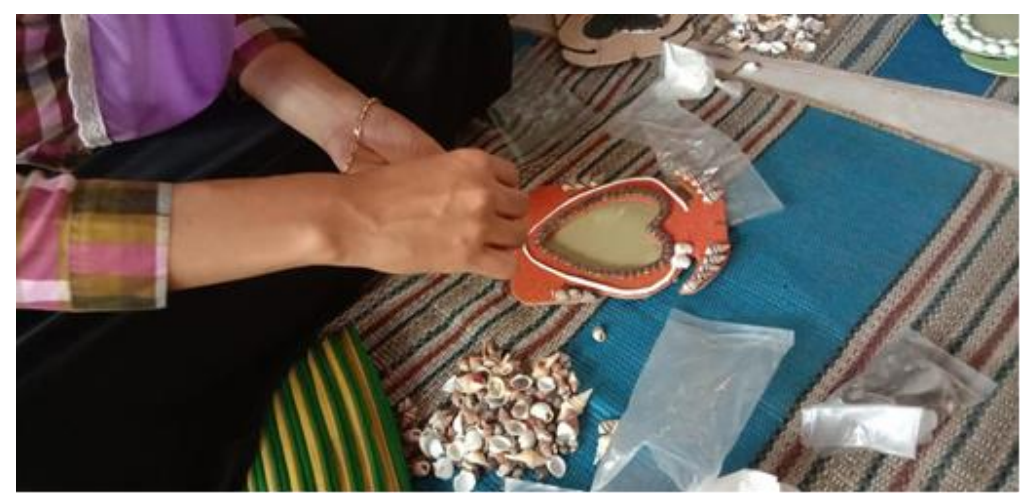

\section{Gambar 3. Cara Pembuatan Hiasan Kerang pada Bingkai Foto}

\section{HASIL DAN PEMBAHASAN}

Hasil Kerajinan Kerang mempunyai dampak yang sangat positif, dimana setiap kerajinan memiliki nilai tambah bagi masyaraat setempat, disamping nilai seni yang tinggi. Hasil kerajinan bisa di liat gambar di bawah ini :
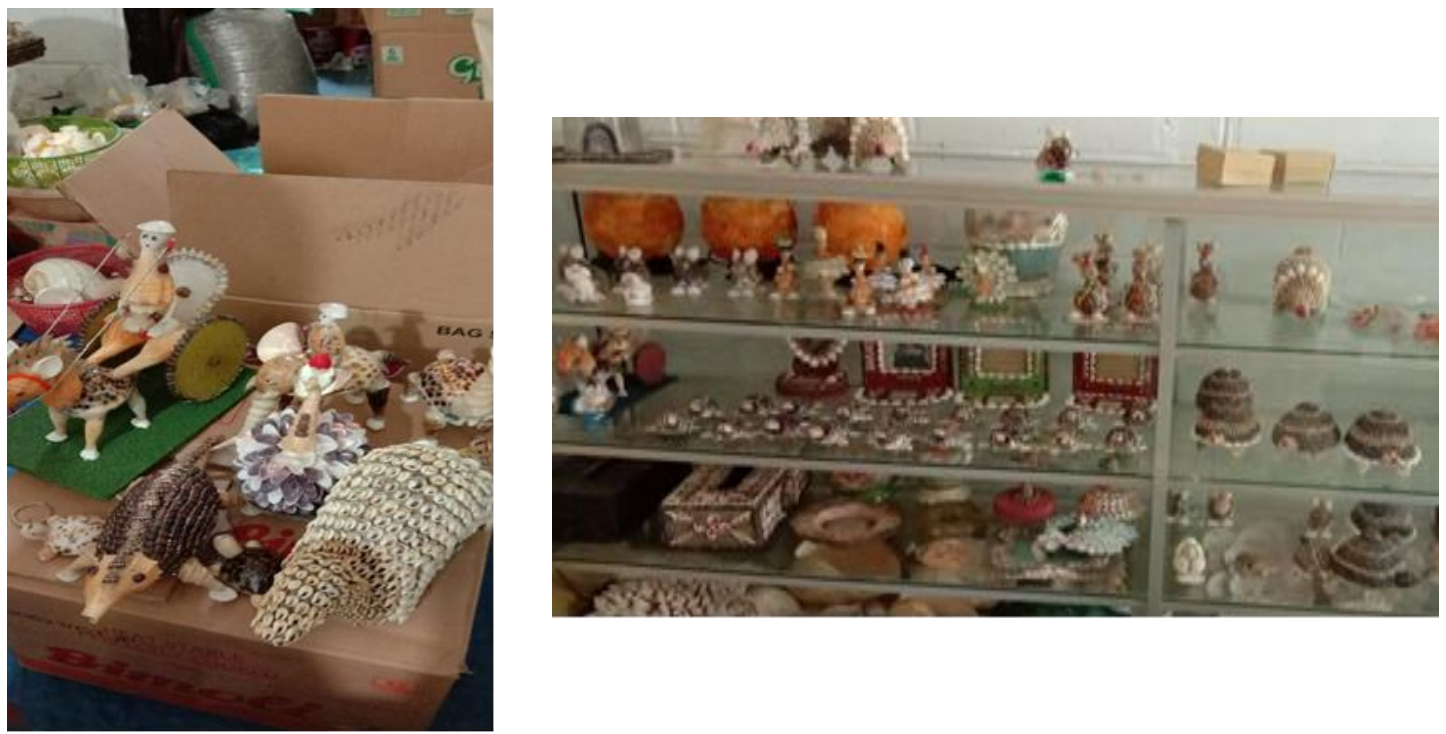

Gambar 4. Macam-Macam Hasil Kerajinan Kerang 
Dengan meingkatnya taraf hidup manusia, menuntut persyaratan-persyaratan yang lebih tinggi terhadap barang-barang kebutuhan kehidupan termasuk barang-barang souvernir atau interior, maka akan memacu tumbuh berkembangnya usaha-usaha di bidang kerajinan serta memacu kreativitas seniman atau designer produk kerajinan yang market oriented. Untuk meraih peluang pasar serta mencari bahan baku alternative yang memiliki nilai tambah tinggi, yaitu pemanfaatan berbagai limbah seperti limbah dari hasil laut berupa kerang-kerangan. Kerang-kerangan yang biasa ditemui di pantai dapat dibuat menjadi kerajinan tangan berupa apa saja, sesuai kreativitas masing-masing.

\section{DAFTAR PUSTAKA}

"Pusat Pelatihan Mandiri Kelautan dan Perikanan" (P2MKP) Karya Virgo. Bidang Kerajinan Kerang. Nono Prihartono. 2018.

https://ms.wikipedia.org/wiki/Karang_Suraga. Dikutip pada tgl 8 Februari 2020 jam 09.30 https://resepkoki.id/8-jenis-kerang-yang-biasa-dikonsumsi-di-indonesia/.Dikutip tgl. 7 Februari 2020 jam 18.30 